\title{
Chronic myeloid leukemia following liver transplantation: A case report
}

\author{
LING ZHANG ${ }^{*}$, BING LONG ${ }^{*}$, XIAO-QING LI, ZHI-GANG FANG, WEN-XING LAI and DONG-JUN LIN \\ Department of Hematology, The Third Affiliated Hospital of Sun Yat-sen University, \\ Guangzhou, Guangdong 510630, P.R. China
}

Received August 13, 2017; Accepted October 19, 2017

DOI: $10.3892 /$ mco.2017.1465

\begin{abstract}
Long-term utilization of immunosuppression in organ transplant recipients leads to decreased immune-mediated tumor surveillance and increased risk of developing malignant tumors. However, chronic myeloid leukemia (CML) following living donor liver transplantation (LDLT) is rarely reported. The current case report presents a 42-year-old male patient who developed CML 14 months following LDLT. The patient achieved complete hematologic remission and early molecular response at 3 months imatinib treatment and major molecular response at 12 months imatinib treatment. The pathogenesis, risk factors, treatment and prognosis for CML following liver transplantation are unclear. Therefore, further analysis through accumulation of cases will be of great importance to prevent and treat this rare complication following liver transplantation.
\end{abstract}

\section{Introduction}

Recent advances in the long-term survival of organ transplant recipients have led to an increased incidence of malignant tumors after transplantation (1). The incidence of de novo tumors has been reported to be ranging from 2.6 to $11.5 \%$ in liver transplant recipients (2). The most common malignancy diseases after transplantation are solid tumors, including lymphoproliferative disease, skin cancers and sarcomas (3). However, chronic myeloid leukemia (CML) is a rare complication after liver transplantation. The first case of CML after liver transplantation was reported in 2007 (4), after that two cases of post transplantation CML has been reported $(5,6)$.

Correspondence to: Professor Dong-Jun Lin, Department of Hematology, The Third Affiliated Hospital of Sun Yat-sen University, No. 600 Tianhe Road, Guangzhou, Guangdong 510630, P.R. China

E-mail: zhang1389@mail.sysu.edu.cn

*Contributed equally

Key words: chronic myeloid leukemia, liver transplantation, immunosuppression
Here we report a 42-year-old male patient who developed CML 14 months after liver transplantation.

\section{Case report}

A 42-year-old male patient presented with a hepatitis B virus related acute liver failure, was admitted to our hospital on October 1, 2014. Blood tests at the diagnosis revealed: white blood cell (WBC) 7.4x109/1, with 17.4\% lymphocytes, $71.9 \%$ neutrophils and no immature cells. Liver function test showed: ALT $1287 \mathrm{U} / 1$, AST $1063 \mathrm{U} / 1$, TBIL $327.2 \mu \mathrm{mol} / 1$, DBIL $244 \mu \mathrm{mol} / 1$, IBIL $83.2 \mu \mathrm{mol} / 1$. Conservative treatment was invalid. On November 21, 2014, the patient accepted a living donor liver transplantation (LDLT). After LDLT, the patient achieved normal liver function: ALT $23 \mathrm{U} / 1$, AST $15 \mathrm{U} / 1$, TBIL $14.2 \mu \mathrm{mol} / 1$, DBIL $8.86 \mu \mathrm{mol} / 1$, IBIL $5.3 \mu \mathrm{mol} / 1$. The immunosuppressive therapy comprised tacrolimus, mycophenolate mofetil and prednisone. A biopsy of hepatic revealed chronic severe hepatitis accompanied nodular cirrhosis.

In December 2015, 12 months after transplantation, the patient's blood test revealed leukocytosis at $12.45 \times 10^{9} / 1$. At 14 months posttransplantion, his white blood cell (WBC) increased to $37.49 \times 10^{9} / 1$, with $79.2 \%$ neutrophils, $8.7 \%$ lymphocytes, $4.8 \%$ monocytes, $3.1 \%$ eosinophils, $4.2 \%$ basophils and $22.7 \%$ immature granulocyte. Liver function test revealed normal limits: ALT $16 \mathrm{U} / 1$, AST $30 \mathrm{U} / 1$, TBIL $11.1 \mu \mathrm{mol} / 1$, DBIL $2.6 \mu \mathrm{mol} / 1$, IBIL $8.6 \mu \mathrm{mol} / 1$. Bone marrow (BM) aspirate showed massive infiltration of neutrophils, eosinophils and basophils, which confirmed the diagnosis of chronic myeloid leukemia (CML) in chronic phase. Genetic testing revealed BCR-ABL (P210) positive by polymerase chain reaction (PCR). The quantitative of BCR-ABL transcript was $31.763 \%$. The mutation of BCR-ABL kinase region was negative. Chromosome analysis showed 46, XY, t (9;22) (q34; q11.2) (Fig. 1). A diagnosis of chronic myeloid leukemia (CML) in chronic phase was made.

The patient received imatinib $400 \mathrm{mg}$ once daily. After 1 month treatment, the WBC count decreased to $3.81 \times 10^{9} / 1$. The patient achieved complete hematologic remission (CHR) after 3 months imatinib treatment, and continuous CHR thereafter. Liver function test was within normal limits: ALT $14 \mathrm{U} / 1$, AST $20 \mathrm{U} / 1$, TBIL $15.9 \mu \mathrm{mol} / 1$, DBIL $6 \mu \mathrm{mol} / 1$, IBIL $9.9 \mu \mathrm{mol} / 1$. At 3 months post imatinib treatment, the quantitative of BCR-ABL transcript had decreased to $2.7838 \%$, consistent with early molecular response (EMR). 12 months 
after imatinib treatment, the patient's BCR-ABL transcript had been $<0.1 \%$, consistent with major molecular response (MMR). At 30 months posttransplantion, the patient is alive with no graft rejection. He remains CHR 13 months after the diagnosis of CML. His current therapy includes imatinib, tacrolimus, mycophenolate mofetil and prednisone.

\section{Discussion}

With the increasing number of long-term survivors of transplantation, the incidence of malignancy disease post transplantation is higher. The most common malignancy diseases after solid organ transplantation are solid tumors, including lymphoprolifer-ative disease, skin cancers and sarcomas (3). While the subsequent malignancy diseases after HSCT are solid tumors, post-transplant lymphoproliferative disease (PTLD) and hematologic malignancies (7). The annual incidence of CML ranges from 0.35 to 0.55 per 100,000 in Chinese population (8). There was no report about the incidence of CML post LDLT, just few case reports, so CML is a rarely complication after LDLT.

There were many hypotheses regarding the development of malignancies in LDLT recipients. Immunosuppressive medications were regarded as the most important risk factor for malignancies after transplantation (9). The role of immunosuppressants in the leukemogenesis has not been elucidated. Mycophenolate mofetil is an inhibitor of hypoxanthine nucleotide dehydrogenase highly expressed in the leukemia, which can develop an anti-leukemia effect (10). Our patient received Mycophenolate mofetil as immunosuppressive therapy. Whether Mycophenolate mofetil can reduce the incidence of leukemia after transplantation needs to be studied further. Moreover, viral infections have been reported to be associated with malignancies after transplantation, such as Epstein-Barr virus, human herpes virus-8, and Papillomaviruses (11). The correlation between hepatitis virus infection and CML deserved further investigation. Some reported cases of leukemia after transplantation have associated chromosomal abnormalities, for example trisomy 8 , monosomy $7, \mathrm{t}(15 ; 17)$, inv $(16)$ and $t(9 ; 22)(12,13)$. Our patient had chromosomal abnormalities involving Philadelphia chromosome.

The most common presentation is leukocytosis or thrombocytosis in the chronic phase of CML. Our patient presented with leukocytosis for two months with no clinical symptoms. Once the diagnosis of CML was confirmed, the patient prompty received imatinib treatment. Effective immunosuppressive therapy greatly reduced the incidence of graft rejection and improved survival time, however, cancer and infections may increase. Some authors reduced tacrolimus to the minimized dosage to maintain stable liver function during acute leukemia chemotherapy (14). Imatinib had been used as a first-line treatment for newly diagnosed CML. However, several cases of hepatotoxicity, including acute liver failure have been reported in the long term imatinib therapy (15). Imatinib-induced acute liver failure is a rare and serious complication of imatinib therapy. Our patient received the same dosage of immunosuppressants during imatinib treatment, and his liver function was normal. The early diagnosis and timely treatment of leukemia post transplantation may significantly reduce mortality (16).

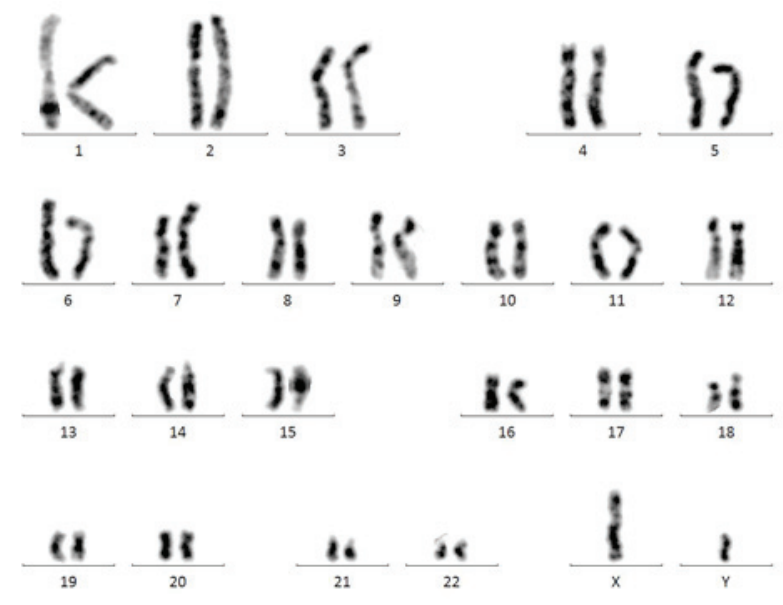

Figure 1. Chromosome karyotype analysis showed 46, XY, t (9;22) (q34; q11.2).

The pathogenesis, risk factors, treatment and prognosis for CML post liver transplantation are unclear. Therefore, further analysis through accumulation cases will be of great importance to prevent and treat this rare complication after liver transplantation.

\section{Acknowledgements}

We thank the members of the Department of Hematology, The Third Affiliated Hospital, Sun Yat-sen University for their critical comments. The present study was supported by the Science and Technology Planning Project of Guangzhou city (No. 201604016070) to Dr X.-W. Jiang.

\section{References}

1. Penn I: Posttransplant malignancies. Transplant Proc 31: 1260-1262, 1999 .

2. Kauffman HM, Cherikh WS and Cheng Y: Posttransplantation malignancies: A problem, a challenge, and an opportunity. Liver Transpl 8: 488-490, 2002.

3. Jiang N, Li H, Wang GS, Zhang J, Zhang JF, Yi SH, Yang Y, Cai CJ, Lu MQ and Chen GH: Acute leukemia, a rare but fatal complication after liver transplantation. Leuk Res 33: 1349-1351, 2009.

4. Concejero A, Chen CL, Wang CC, Wang SH, Lin CC, Liu YW, Yang CH, Yong CC, Wang MC and Eng HL: Chronic myeloid leukemia after living donor liver transplantation. Transplantation 83: 1521-1522, 2007.

5. le Coutre P, Reinke P, Neuhaus R, Trappe R, Ringel F, Lalancette M, Hemmati PG, Dörken B and Daniel PT: BCR-ABL positive cells and chronic myeloid leukemia in immune suppressed organ transplant recipients. Eur J Haematol 84: 26-33, 2010.

6. Chiefer J, Mathers E, Bras P and Milan Z: Re-do liver transplantation in a young patient with chronic myeloid leukemia following a recent sepsis episod. Edorium J Anesth 2: 25-27, 2016.

7. Gündüz M, Özen M, Sahin U, Toprak SK, Civriz Bozdağ S, Kurt Yüksel M, Arslan Ö, Özcan M, Demirer T, Beksaç M, et al: Subsequent malignancies after allogeneic hematopoietic stem cell transplantation. Clin Transplant 31: e12987, 2017.

8. Yin XF, Wang JH, Li X, Yu MX, Ma ZX and Jin J: Incidence of second malignancies of chronic myeloid leukemia during treatment with tyrosine kinase inhibitors. Clin Lymphoma Myeloma Leuk 16: 577-581, 2016.

9. Cho YU, Chi HS, Park CJ, Seo EJ, Lee JH, Lee JH and Lee SG: Two cases of post-liver transplant acute myeloid leukemia in korean adults: Review of bibliographies and comparison with post-renal transplant acute myeloid leukemia. Ann Hematol 87: 513-514, 2008. 
10. Floryk D and Thompson TC: Antiproliferative effects of AVN944, a novel inosine 5-monophosphate dehydrogenase inhibitor, in prostate cancer cells. Int J Cancer 123: 2294-2302, 2008.

11. Liu M, Liu J, Liu L, Yu L, Shi B, Ye L, Zhang Y and Chen H: A case report of acute myeloid leukemia after liver transplantation. Acta Haematol 129: 225-228, 2013.

12. Thalhammer-Scherrer R, Wieselthaler G, Knoebl P, Schwarzinger I, Simonitsch I, Mitterbauer G, Berlakovich GA, Mannhalter C, Haas OA, Mayer G, et al: Post-transplant acute myeloid leukemia (PT-AML). Leukemia 13: 321-326, 1999.

13. Silliman CC, Tyson RW, Wei Q, Karrer FG, Davies SM, Blake M and McGavran L: Acute Philadelphia chromosome-positive leukemia in an adolescent boy after liver transplantation. J Pediatr Hematol Oncol 25: 565-568, 2003.

14. Zhang GS, Dai CW,Peng HL, Xu YX and Pei MF: Myelodysplastic syndrome with transformation to acute monocytic leukemia with FLT3-ITD mutation following orthotopic liver transplantation. Leuk Res 30: 908-910, 2006.
15. Fuster F, Medina L, Vallansot R, Granell $\mathrm{M}$ and Bruguera $\mathrm{M}$ : Imatinib-induced toxic hepatitis: Description of two cases and review of the literature. Gastroenterol Hepatol 30: 525-530, 2007 (In Spanish).

16. Fang Y, Pinkney KA, Lee JC, Gindin T, Weiner MA, Alobeid B and Bhagat G: T-cell acute lymphoblastic leukaemia after liver transplantation: Post-transplant lymphoproliferative disorder or coincidental de novo leukaemia? Hematol Oncol 31: 49-53, 2013. 